\title{
Subcutaneous Emphysema
}

\author{
S. M. Balaji
}

Received: 15 October 2010/Accepted: 9 December 2010/Published online: 22 March 2011

(C) Association of Oral and Maxillofacial Surgeons of India 2011

\begin{abstract}
Subcutaneous emphysema is a potential surgical complication arising due to introduction of air into the facial planes of the connective tissue. presence of air and accompanying inflammation and or infection could prove fatal in immediate post surgical scenario. This case report aims to prevent one such case of subcutaneous emphysema that was promptly diagnosis and effectively managed.
\end{abstract}

\section{Introduction}

Subcutaneous emphysema (SE) was previously described as pneumomediastinum. Laenec, in 1827, termed the disease 'inter-lobar emphysema' $[1,2]$. Introduction of air into the facial planes of the connective tissues of head and neck results in SE. It is a serious complication and side effects of oral and surgical procedure [3]. Because of the looseness of this tissue and its distensible walls, air can accumulate in these crevices and convert them into spaces of considerable size $[4,5]$. The air may gain access to the fascial planes and produce SE in any situation in which the integrity of the oral mucosa is interrupted and intraoral pressure is increased.

The etiology of SE includes trauma (fractures of the facial bones with sinus involvement, neck surgery, penetrating gunshot injuries of head and neck, chest, penetrating trauma to the gastrointestinal or respiratory systems), iatrogenic (anesthesia either during endotracheal/naso-tracheal intubation, or laparoscopy - tearing of the tracheal

S. M. Balaji $(\square)$

No: 30 KB Dasan Road, Teynampet, Chennai 600018, India

e-mail: smbalaji@gmail.com mucosa during intubation, increased pressure in the alveoli because of excessive ventilation pressure, improper chest tube placement during chest surgery, dental high speed hand pieces), incidental [barotrauma (diving, positive pressure ventilation), labor, foreign body] and pathological causes (anaerobic, clostridia, mixed, gas-forming facultative aerobic infections) [1].

\section{Case Report}

A 24 year old female patient underwent lefort 1 osteotomy for correction of dentofacial deformity (vertical and horizontal maxillary deficiency). During the immediate post operative period the patient developed sudden swelling on both sides of the face, extending into the neck and sternum. On examination there was no respiratory distress, but on palpation crepitation was felt in the head and neck region which was rapidly spreading. A diagnosis of SE was made. The patient was immediately shifted into the operation theatre.

Under local anesthesia, multiple stab incision was placed in the neck region to decompress spreading emphysema, and to allow adequate air escape. The swelling subsided immediately and the patient was discharged. She reported after 3 days with swelling in both her hands and shoulder region. On bronchoscopic examination, a tear in the posterior tracheal wall was noticed just below the epiglottis. The injury occurred during intubation. The patient underwent surgical tracheostomy in which the outer inlet tracheostomy tube was placed against the mucosal tear in the trachea. After 10 days on bronchoscopic examination, after removing the tracheostomy tube, the tear on the posterior tracheal wall had healed well without any further complications (Figs. 1, 2, 3). 

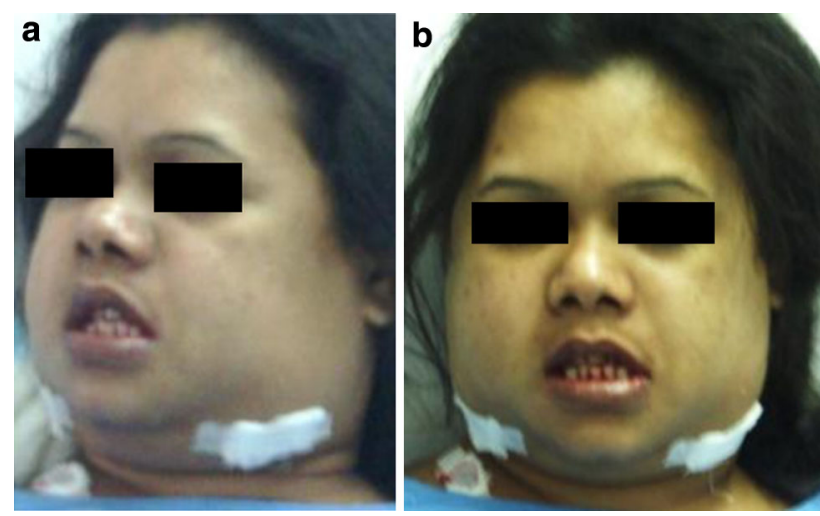

Fig. 1 a, b Pre-operative frontal view

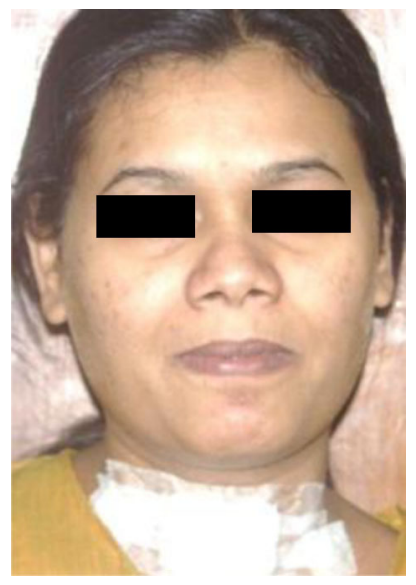

Fig. 2 Immediate post-operative view

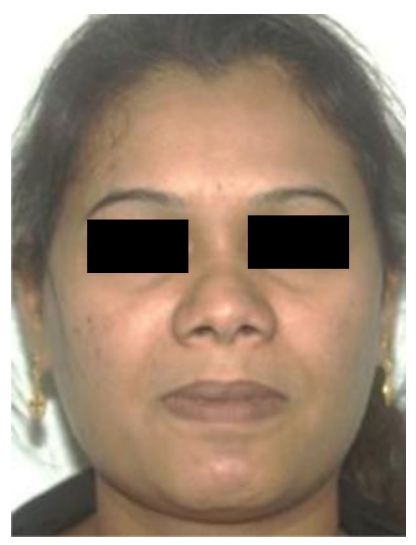

Fig. 3 Post-operative view after 5 days

\section{Discussion}

During dental treatment there are possibilities for the occurrence of SE. The reason for the occurrence of SE during routine dental treatment is mainly due to increase in intraoral pressure at the site of a mucosal injury or the allowance of compressed air into an intraoral wound. SE can also be induced by the patient coughing, blowing forcefully, smoking, or vomiting after a dental procedure. Procedures such as extractions and oral surgery procedures, orthognathic surgery [6, 7], endodontic therapy [8, 9], crown preparation especially use of air driven hand pieces, lacerations of soft tissue during dental operations [10], during scaling and root planning therapy [11], result of facial injuries $[12,13]$ and those related to ventilation with endotracheal intubation for general anesthesia [14].

Fractures of the facial skeleton are considered potential source of SE of the head and neck area. Maxillary, ethomoidal, frontal sinuses nasal-orbital ethomoidal complex and zygomaticomaxillary complex involving the lateral wall of the maxillary sinus fractures cause SE more often [1]. Para-nasal sinuses are the vital area and it does provide the source of initiating air diffusion within facial tissues. Through the injury following fracture the air may be forced into the tissue spaces of the face and the eyelid, especially those of the periorbital region which are prone to inflation since they are loose areolar tissue. Most commonly the periorbital SE occurs through a defect in the medial orbital wall from the ethomoidal sinuses and, less frequently, from the maxillary sinus or retro-septally. After mid-facial fractures, SE usually occurs during a brief period post traumatically when air can be forced into the tissues. After this, the escape routes became sealed by blood clots in the sinuses and the fracture sites. SE is a potential complication of procedures that interrupt the epithelium of the oral cavity and introduces air, under pressure, along or into the facial spaces of head and neck.

Allergic reaction, hematoma, angioedema, esophageal rupture and infectious necrotizing fasciitis are the common differential diagnosis of this condition. SE is generally self-limiting and benign, but also results in serious local and systemic complications. They include loss of vision, cranial nerve weakness, pneumothorax, pneumomediastinum and infection secondary to contaminated air diffusion [4].

When SE does arise, it must be quickly diagnosed, and effectively managed to reduce the incidence of further complications. Treatment protocol of SE involves airway management, infection prophylaxis, and radiologic assessment. Treatment of SE is conservative and observatory. If the condition is not treated, it can lead to a compromised airway, pneumomediastinum, or, even, pneumothorax [15]. Most cases of SE, although alarming, usually resolve spontaneously in 3-5 days with no complications or morbidity, and complete recovery in 7-10 days [3].

Treatment modalities of SE include (i) monitoring the oxygen saturation, (ii) broad spectrum antibiotic coverage for prophylaxis (penicillin, or cephalosporin), (iii) $100 \%$ oxygen therapy, (iv) hydration with intravenous fluids for 
conditions including dysphagia, orofacial edema and laryngeal damage and systemic steroids to reduce the soft tissue edema.

\section{References}

1. Patel N, Lazow SK, Berger J (2010) Cervicofacial subcutaneous emphysema: case report and review of literature. J Oral Maxillofac Surg 68(8):1976-1982

2. Minton G, Tu HK (1984) Pneumomediastinum, pneumothorax, and cervical emphysema following mandibular fractures. Oral Surg Oral Med Oral Pathol 57(5):490-493

3. Stuart McKenzie Wm, Rosenberg M (2009) Iatrogenic subcutaneous emphysema of dental and surgical origin: a literature review. J Oral Maxillofac Surg 67:1265-1268

4. Brasileiro BF, Cortez AL, Asprino L, Passer LA, De Moraes M, Mazzonetto R, Moreira RW (2005) Traumatic subcutaneous emphysema of the face associated with paranasal sinus fractures: a prospective study. J Oral Maxillofac Surg 63:1080-1087

5. Paquette M, Terazhalmy GT, Moore WS (2002) Subcutaneous emphysema. Quintessence Int 33(6):478-479

6. McLoughlin PM, Gilhooly MG (1984) Surgical emphysema complicating mandibular sagittal split osteotomy. Br J Oral Surg 22(4):269-273

7. Edwards DB, Scheffer RB, Jackler I (1986) Postoperative pneumomediastinum and pneumothorax following orthognathic surgery. J Oral Maxillofac Surg 44(2):137-138
8. Bhat KS (1974) Tissue emphysema by hydrogen peroxide. Oral Surg Oral Med Oral Pathol 38(2):304-307

9. Falomo OO (1984) Surgical emphysema following root canal therapy. Report of a case. Oral Surg Oral Med Oral Pathol 58(1):101-102

10. Horowitz I, Hirshberg A, Freedman A (1987) Pneumomediastinum and subcutaneous emphysema following surgical extraction of mandibular third molars: three case reports. Oral Surg Oral Med Oral Pathol 63(1):25-28

11. Liebenberg WH, Crawford BJ (1997) Subcutaneous, orbital and mediastinal emphysema secondary to the use of an air-abrasive device. Quintessence Int 28(1):31-38

12. Monaghan AM, Millar BG (2002) Orbital emphysema during air travel: a case report. J Craniomaxillofac Surg 30(6):367-368

13. Roccia F, Griffa A, Nasi A, Baragiotta N (2003) Severe subcutaneous emphysema and pneumomediastinum associated with minor maxillofacial trauma. J Craniofac Surg 14(6):880-883

14. Reiche-Fischel O, Helfrick JF (1995) Intraoperative life-threatening emphysema associated with endotracheal intubation and air insufflation devices: report of two cases. J Oral Maxillofac Surg 53(9):1103-1107

15. Anderson JA, Tucker MR, Foley WL, Pillsbury HC 3rd, Norfleet EA (1991) Subcutaneous emphysema producing airway compromise after anesthesia for reduction of a mandibular fracture. A case report and review of the literature. Oral Surg Oral Med Oral Pathol 71(3):275-279 